\title{
3. CALIBRATION OF AN X-RAY DIFFRACTION METHOD TO DETERMINE RELATIVE MINERAL ABUNDANCES IN BULK POWDERS USING MATRIX SINGULAR VALUE DECOMPOSITION: A TEST FROM THE BARBADOS ACCRETIONARY COMPLEX ${ }^{1}$
}

\author{
Andrew T. Fisher ${ }^{2}$ and Michael B. Underwood ${ }^{3}$
}

\begin{abstract}
$\mathrm{X}$-ray diffraction methods are used routinely to identify detrital and authigenic minerals in bulk powders of marine sediment. Semiquantitative bulk XRD analysis, however, is difficult. We employed a mathematical technique using matrix singular value decomposition to solve for reliable normalization factors, thereby allowing accurate conversion of XRD data to relative mineral abundances. Calibration was achieved through measurements of laboratory mixtures with known abundances of mineral standards. Error analysis demonstrates that this method is superior to other common shipboard procedures used by the Ocean Drilling Program; the errors from known standards fall within the range of analytical reproducibility and are better than $3 \%$.
\end{abstract}

\section{INTRODUCTION}

$\mathrm{X}$-ray diffraction (XRD) is an essential tool for determining the presence or absence of detrital and authigenic minerals within bulk samples of marine sediment. The method is fast, inexpensive, and a routine part of Ocean Drilling Program (ODP) shipboard operations. Because the required sample volumes are relatively small, XRD analysis can be completed on sample residues from other analyses, such as tests of index properties or carbon-carbonate content.

Identification of specific minerals on diffractograms is accomplished routinely through the recognition of characteristic peak positions, either by eye or through a computerized match with standard $\mathrm{XRD}$ responses. It is much more difficult to calculate relative mineral abundances. Often, qualitative results are shown in a table with symbols to indicate categories such as "dominant," "abundant," "minor," and "trace," but some scientists convert these categories to numerical values and plots. In addition, there is no consistency between assessments of different workers. Peak intensities and peak areas can be used as indicators of mineral abundance, but relations among peaks for multicomponent mixtures can be very complicated. For a single mineral, each individual peak will display a different geometry. In a mineral mixture, the intensity of any given peak will be influenced by its own abundance, the absolute abundance, crystallinity, and orientation of all other minerals in the specimen, and the amount of amorphous solids such as volcanic glass and opal. With bulk powders, additional problems are encountered if the analyses include both platy minerals, such as clays, and nonplaty minerals such as quartz, feldspar, and carbonates. Platy minerals produce the best XRD results when analyzed as oriented aggregates, whereas nonplaty minerals should be analyzed as random mounts.

Many techniques have been proposed to improve quantification of bulk mineralogy and clay mineralogy (Pierce and Siegel, 1969; Brindley, 1980). One approach is to derive peak-intensity weighting factors from 50:50 mixtures of two mineral standards (e.g., Cook et al., 1975). The typical mineral for comparison is quartz. This approach is flawed, however, because the error attached to the single weighting factor for each mineral pair increases as the mixture deviates from the ideal 50:50 blend. A second method involves spiking samples with a

\footnotetext{
' Shipley, T.H., Ogawa, Y., Blum, P., et al., 1995. Proc. ODP, Init. Repts., 156: College Station, TX (Ocean Drilling Program).

${ }^{2}$ Department of Geological Sciences and Indiana Geological Survey, Indiana University, Bloomington, IN 47405, U.S.A.

${ }^{3}$ Department of Geological Sciences, University of Missouri, Columbia, MO 65211 , U.S.A.
}

known weight percentage of a foreign mineral such as talc or corundum; weighting factors then can be calculated from the talc-normalized peak areas (Heath and Pisias, 1979). These weighting factors, however, will change with the relative abundance of the spike mineral. Single best-fit weighting factors can be determined for each individual mineral in a known multicomponent mix using laboratory blends of mineral standards (e.g., Underwood et al., 1993). Linear interaction coefficients for every mineral pair in a multicomponent system also can be determined empirically (Moore, 1968); accuracy improves if each mineral pair is measured over its entire range of possible mixtures. Mineral intensity factors likewise can be calculated from theoretical mineral reference intensities using computer programs such as NEWMOD (Moore and Reynolds, 1989). Many of the software packages that support modern digital XRD systems also can be calibrated using results from known mixtures of standard minerals (e.g., Mascle et al., 1988); unfortunately, the inner workings of these programs are generally protected by proprietary status, so they are impossible to evaluate. A final method involves the use of simultaneous linear equations, and the input parameters can include both XRD and chemical data (Johnson et al., 1985). With this approach, the minimum number of properties measured must equal the number of components in the samples being analyzed, and the minimum number of samples analyzed must equal the number of properties measured (e.g., peak intensity for three minerals in three standards). This constraint may not allow the full range of natural mineral concentrations to be represented in a limited set of standards. The method described in this paper is a modification of this linear approach. Our new method was used to calculate relative abundances of total clay minerals (smectite, illite, and kaolinite), quartz, plagioclase, and calcite, as reported in the respective site chapters in this volume.

\section{Mathematical Determination of Optimal Normalization Factors}

Like Johnson et al. (1985), we used linear algebra to determine factors for converting XRD data to relative mineral abundances. Absolute abundances are virtually impossible to quantify without identifying every mineral phase in the specimen, along with the weight percentages of each amorphous constituent; this is an unrealistic goal for ODP shipboard investigations. Our goal was to reproduce bulk abundances of known standards to better than the analytical accuracy of the bulk measurements.

To calculate relative proportions, we assumed first that there is a consistent and quantifiable relationship between one chosen XRD indicator (peak intensity or peak area) and the actual relative abun- 
dance of each mineral of interest. Next, we assumed that the strength of the signal for one mineral is influenced by the strength of the signals for all other minerals in the same sample. The nature of this influence can be either positive or negative in terms of the signal indicator. Finally, we assumed that the factors that allow conversion from XRD signals to actual mineral abundances are constants. This last assumption is perhaps the weakest; nevertheless, the use of constant factors allowed us to predict mineral abundances for a set of reference mineral mixtures, spanning a wide range of compositions, with a degree of accuracy better than the experimental reproducibility of the instrument and the supporting software used to reduce digital output. Later we discuss how one might relax this last assumption, through iterative analysis, to calculate XRD factors that vary with mineral abundances in a relationship that follows a linear, polynomial, exponential, or practically any other mathematical form.

A specific example should make these assumptions and relationships clear. Assume that Sample 1 contains unknown proportions of quartz, plagioclase, and calcite, but no other minerals. One specific peak must be chosen for each mineral as the indicator of its relative abundance. The relationship among the three signals and the abundance of quartz in Sample 1 is:

$$
S_{Q 1} F_{Q Q}+S_{P I} F_{P Q}+S_{C I} F_{C Q}=A_{Q I},
$$

where $S_{X I}$ is the signal from each mineral in Sample $1, F_{X Q}$ is the factor for each mineral as an indicator of quartz, $X$ is the mineral responsible for the signal in question ( $Q=$ quartz, $P=$ plagioclase, and $C=$ calcite), and $A_{Q I}$ is the true abundance of quartz in Sample 1. Thus, if we know the values of the various factors, $F_{X Q}$, we can calculate the abundance of quartz from the diffractogram of the sample. Similar equations are used to determine the abundances of the other two minerals in Sample 1. The XRD signals from the sample remain the same, but the factors are different: $F_{C C}=$ the factor for calcite as an indicator of calcite, $F_{Q C}$ $=$ the factor for quartz as an indicator for calcite, etc. The problem, then, is to determine values for these various factors that will allow accurate conversion from XRD signals to actual abundances over the range of standard mixtures.

As a first step, one can determine the values of the various factors independently for each target mineral, beginning with quartz. If a set of three or more standards is mixed, each with different proportions of the three minerals, then we will have three or more equations with three unknowns. With three standards, we have an exactly determined system. With four or more standards we have an over determined system, and the solution will optimize the values of the factors in order to minimize the difference between actual and predicted quartz abundances in the set of standards. With a set of four standards we have for quartz four equations and three unknowns:

$$
\begin{aligned}
& S_{Q 1} F_{Q Q}+S_{P I} F_{P Q}+S_{C 1} F_{C Q}=A_{Q 1}, \\
& S_{Q 2} F_{Q Q}+S_{P 2} F_{P Q}+S_{C 2} F_{C Q}=A_{Q 2}, \\
& S_{Q 3} F_{Q Q}+S_{P 3} F_{P Q}+S_{C 3} F_{C Q}=A_{Q 3}, \\
& S_{Q 4} F_{Q Q}+S_{P 4} F_{P Q}+S_{C 4} F_{C Q}=A_{Q 4} .
\end{aligned}
$$

Similar sets of equations can be generated for the other two minerals.

For the Leg 156 samples, we blended six standard minerals (quartz, plagioclase, calcite, smectite, illite, and kaolinite) into nine standard mixtures (Table 1). The selection and compositions of these mineral standards are based on earlier XRD studies near the Leg 156 sites. The combination of six standard minerals and nine mixtures gives nine equations and six unknowns. For quartz abundance determination, the matrix representation of these equations is:

$$
\mathbf{S} \cdot \mathbf{F}_{Q}=\mathbf{A}_{Q},
$$

where $\mathbf{S}$ is a rectangular $(m \times n)$ matrix of signals from $m$ standard mixtures (rows) and $n$ standard minerals (columns), $\mathbf{F}_{Q}$ is a vector of $n$ factors, one for each mineral as an indicator of quartz abundance, and $\mathbf{A}_{Q}$ is a vector of $m$ quartz abundances, one for each standard mixture. This matrix equation can be inverted numerically to determine the values of the solution vector, $\mathbf{F}_{Q}$, using singular value decomposition (SVD) (Press et al., 1986), such that:

$$
\mathbf{F}_{Q}=\mathbf{V} \cdot \mathbf{W} \cdot \mathbf{R}^{T} \cdot \mathbf{A}_{Q} .
$$

With this construction, $\mathbf{V} \cdot \mathbf{W} \cdot \mathbf{R}^{T}$ is equivalent to $\mathbf{S}^{-1}, \mathbf{V}$ is a column-orthogonal matrix with the same dimensions as $\mathbf{S}, \mathbf{W}$ is an $n$ $\times n$ diagonal matrix containing inverse singular values $\left(1 / w_{n}\right)$, and $\mathbf{R}^{T}$ is the transpose of an $n \times n$ orthogonal matrix. Similar constructions can be made for the vectors containing factors for the other minerals: $\mathbf{F}_{P}, \mathbf{F}_{C}, \mathbf{F}_{S}, \mathbf{F}_{l}$, and $\mathbf{F}_{K}$. In this way, the calculated abundance of a given mineral is not only influenced by the intensity or area of its diagnostic peak, it is also influenced by the signals generated by other mineral components in the system.

One shortcoming to this approach is that the indicator factors for each mineral are calculated independently of those for the other minerals. To compensate, we added an additional constraint to the system; the total of all mineral abundances should add up to $100 \%$ for each standard mixture. We then solved for all factors simultaneously. This was accomplished by creating and solving combined sets of equations, shown in matrix form as:

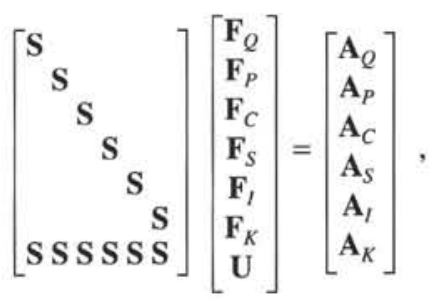

where the combined signal matrix is sparse, single-bordered, and block triangular using the original signal matrix, $\mathbf{S}$. The abundance vector includes abundances for all minerals in all standard mixtures plus the unity constraint, $\mathbf{U}$ (a $1 \times m$ matrix, filled with the value 1 , if decimal fractions are used to indicate abundance, or 100 if percentages are used). A singular factor vector (the desired solution) includes factors for all indicator and target minerals. For the nine standard mixtures analyzed during Leg 156 , the combined signal matrix has 63 rows $(m \times[n+1])$ and $36(n \times n)$ columns; the abundance vector has 63 components and the factor vector has 36 components. With this construction, the unity constraint is not absolute, but instead is given as much influence on the solution as each of the standards. More or less weight could be applied to the unity relation (or to data from any of the standards mixtures or minerals), but as we will demonstrate, the equal weighting applied to our standard mixtures resulted in an excellent match between measured and calculated mineral abundances.

\section{Shipboard Equipment and Mineral Standards}

The X-ray laboratory aboard JOIDES Resolution is equipped with a Philips PW-1729 X-ray generator, a Philips PW-1710/00 diffraction control unit with a PW-1775 35 port automatic sample changer, and a Philips PM-8151 digital plotter. Machine settings for all standards were as follows: generator $=40 \mathrm{kV}$ and $35 \mathrm{~mA}$; tube anode $=\mathrm{Cu}$; wavelength $=1.54056 \AA\left(\mathrm{CuK}_{\alpha 1}\right)$ and $1.54439 \AA\left(\mathrm{CuK}_{\alpha 2}\right)$; intensity ratio $=0.5$; focus $=$ fine; irradiated length $=12 \mathrm{~mm}$; divergence slit $=$ automatic; receiving slit $=0.2 \mathrm{~mm}$; step size $=0.01^{\circ} 2 \theta$; count time per step $=1 \mathrm{~s} ;$ scanning rate $=2^{\circ} 2 \theta / \mathrm{min}$; ratemeter time constant $=0.2$ s; spinner $=$ off $;$ monochrometer $=$ on; scan $=$ continuous; scanning range $=2^{\circ} 2 \theta-35^{\circ} 2 \theta$.

Digital data were processed using a Philips peak-fitting program that subtracts background intensities and fits ideal curve shapes to individual peaks or ranges of peaks, as specified by the operator. 
Table 1. Measured weight percentages for $\mathrm{X}$-ray diffraction mineral standards.

\begin{tabular}{crrrrrrr}
\hline $\begin{array}{c}\text { Standard } \\
\text { ID }\end{array}$ & $\begin{array}{c}\text { Smectite } \\
\text { (wt\%) }\end{array}$ & $\begin{array}{c}\text { Illite } \\
\text { (wt\%) }\end{array}$ & $\begin{array}{c}\text { Kaolinite } \\
\text { (wt\%) }\end{array}$ & $\begin{array}{c}\text { Clay } \\
\text { (wt\%) }\end{array}$ & $\begin{array}{l}\text { Quartz } \\
\text { (wt\%) }\end{array}$ & $\begin{array}{c}\text { Plagioclase } \\
\text { (wt\%) }\end{array}$ & $\begin{array}{c}\text { Calcite } \\
\text { (wt\%) }\end{array}$ \\
\hline 1 & 1.9 & 1.3 & 2.0 & 5.2 & 15.7 & 10.1 & 69.0 \\
2 & 24.9 & 17.7 & 26.7 & 69.3 & 24.9 & 5.8 & 0.0 \\
3 & 11.9 & 8.5 & 12.8 & 33.2 & 40.0 & 13.1 & 13.7 \\
4 & 10.6 & 7.6 & 11.3 & 29.5 & 15.2 & 37.0 & 18.3 \\
5 & 9.4 & 6.7 & 10.1 & 26.2 & 18.5 & 9.0 & 46.3 \\
6 & 43.1 & 4.8 & 5.2 & 53.1 & 37.1 & 5.2 & 4.6 \\
7 & 30.7 & 10.1 & 5.2 & 46.0 & 39.8 & 4.6 & 9.6 \\
8 & 18.1 & 4.8 & 15.1 & 38.0 & 42.0 & 5.6 & 14.4 \\
9 & 61.5 & 0.0 & 0.0 & 61.5 & 38.5 & 0.0 & 0.0 \\
\hline
\end{tabular}

Typically, this program was used over the following scanning angles: $3.5-10.5^{\circ} 2 \theta$ (smectite and illite), $10.5-13.5^{\circ} 2 \theta$ (overlapping kaolinite + chlorite) and $25.5-30.5^{\circ} 2 \theta$ (quartz, plagioclase, and calcite). Curve-fitting is most effective if there are fewer than 750 steps per scanning interval, and iterations continue automatically until a prescribed $\chi^{2}$ test is satisfied. Output of a processed digital data includes the angular position of each peak $\left({ }^{\circ} 2 \theta\right)$, d-spacing $(\AA)$, peak width $\left(\Delta^{\circ} 2 \theta\right)$, intensity or height (counts per second above background), and peak area (total counts above background). Precision of the peak-fitting program deteriorates as peak intensities approach the background noise.

The six minerals selected for our standard mixtures are based on the results of previous bulk-powder and clay-fraction XRD analyses of Deep Sea Drilling Project (DSDP) and ODP specimens from the northern Barbados Ridge (Pudsey, 1984; Capet et al., 1990; Tribble, 1990). The total abundance of each standard mineral in the standard mixtures is shown in Table 1. The quartz standard is National Bureau of Standards (NBS) $\mathrm{SiO}_{2}$ from Hot Springs, AR. Calcite is Wards Iceland spar from Chihuahua, Mexico. Plagioclase is Wards oligoclase from Mitchell County, NC. Illite is Clay Mineral Society (CMS) standard IMt-1. Kaolinite is a mixture of approximately $50 \%$ each poorly crystalline (CMS KGa-1) and well crystalline (CMS KGa-2) kaolinite. The smectite mixture comprises three components in varying proportions: Wards generic montmorillonite from Cameron, AZ (75\%); CMS SWy-2 Na-montmorillonite (13\%-25\%); and CMS SAz-1 Ca-montmorillonite $(0 \%-12 \%)$. All minerals were available either prepowdered or were oven-dried and ground in a ball mill. After weighing and stirring, each standard mixture was blended further in the ball mill for several minutes to produce a powder with uniform texture. Subsamples of each standard mixture were packed into rectangular sample holders, as randomly oriented mounts, and run sequentially. The randomly oriented powders were not pretreated with any chemicals. The powder of each standard mixture was blended a final time before subsamples were extracted; in spite of these precautions, variations in the diffractograms for subsequent slides of the same mixture show that preferential settling of mineral particles did occur, particularly with well crystalline material such as calcite. This phenomenon is extremely difficult to avoid on the JOIDES Resolution because of the constant shipboard vibration. In partial compensation, the average peak areas and average intensities from individual runs were used as input values for the SVD program, with the exception of Standard 9 (montmorillonite and quartz mixture), for which only one subsample was run (Table 2).

Typical diffractograms for each of the nine standards are shown in Figure 1, along with labels indicating the peaks used for specific mineral identification. Standard 9 was a mixture of three montmorillonite mineral "standards" available aboard the ship. Careful examination of diffractograms from each individual component of this smectite mixture revealed that the Wards generic montmorillonite and CMS $\mathrm{Na}$-montmorillonite both contain significant proportions of quartz. We determined the amount of quartz contamination by conducting a series of tests independent of those described below, in which subsamples of generic montmorillonite and Na-montmorillonite powders were spiked with known quantities of quartz to generate mixing curves (Fig. 2 ). The samples were spiked only twice, but all of the mixing curves for peak intensity and peak area are clearly nonlinear. These curves help illustrate the problem associated with using single mixtures of a given mineral pair for calibration of weighting factors; errors increase with increasing deviation from the ideal 50:50 mix. Diffractograms from the spiked subsamples were evaluated along with those from the two unspiked subsamples, using the same SVD technique described in the preceding section. As a result, we concluded that the generic montmorillonite "standard" contains $45 \%$ quartz, whereas the Namontmorillonite "standard" contains $39 \%$ quartz. These montmorillonite/quartz ratios were used to recalculate the compositions of all standard mixtures. For example, when combined with the measured weight of relatively pure $\mathrm{Ca}$-montmorillonite, we determined that the Standard 9 mixture contains $38.5 \%$ quartz (Table 1).

\section{Analyses of Standard Mixtures}

Once the nine standard mixtures were prepared, and the respective diffractograms were generated, the next task was to determine which type of signal provides the most consistent indicator of mineral abundance. Obvious candidates include peak intensity and peak area, but other decisions were less clear-cut. For example, should individual clay-mineral peaks be used (i.e., at approximately $6^{\circ}, 8.5^{\circ}$, and $12^{\circ} 2 \theta$ ), or should one rely on a single composite clay-mineral peak produced by overlapping reflections at approximately $19.8^{\circ} 2 \theta$ ? This peak apparently represents a 020 reflection that is common to several clay minerals. Should mineral signals be normalized or transformed in any way prior to calculation of weighting factors? We elected to take an empirical approach, by examining several alternative strategies; our goal was to find out which method yielded the closest match between measured and calculated mineral abundances. As a target for error reduction, the accuracy of calculated mineral abundances should be no greater than the analytical reproducibility, as dictated by imperfections in sample preparation, machine drift, and peak fitting using Philips software packages. Tests completed during Leg 156 showed that the reproducibility averages $\pm 2.4 \%$ for total clay, $\pm 2.0 \%$ for quartz, $\pm 2.8 \%$ for plagioclase, and $\pm 1.7 \%$ for calcite. These are not the maximum errors associated with using the proposed method for the analysis of unknown mineral samples, but reflect instead our ability to replicate the mineral abundances of known standards. These relatively low errors in reproducibility indicate that the proposed method is statistically stable for the nine standards, and that errors associated with the inversion for standard composition are lower than experimental variations for typical bulk XRD analyses (Table 2).

Results of several approaches are tabulated in Table 3. In that table, and in the following discussion, the calculated individual abundances of smectite, illite, and kaolinite are combined into a total clay component. This was done for two important reasons: to facilitate comparisons with the XRD methodologies of Cook et al. (1975) and Mascle et al. (1988) and because there are unresolved questions of reliability for individual clay-mineral percentages when analyzed as random bulk powders, especially without ethylene glycol solvation. In particular, we were unable to eliminate the effects of overlap between the smectite $(001)$ and illite $(001)$ reflections. The peak interference problem was exacerbated in the most of the Leg 156 claystone 


\section{A.T. FISHER, M.B. UNDERWOOD}
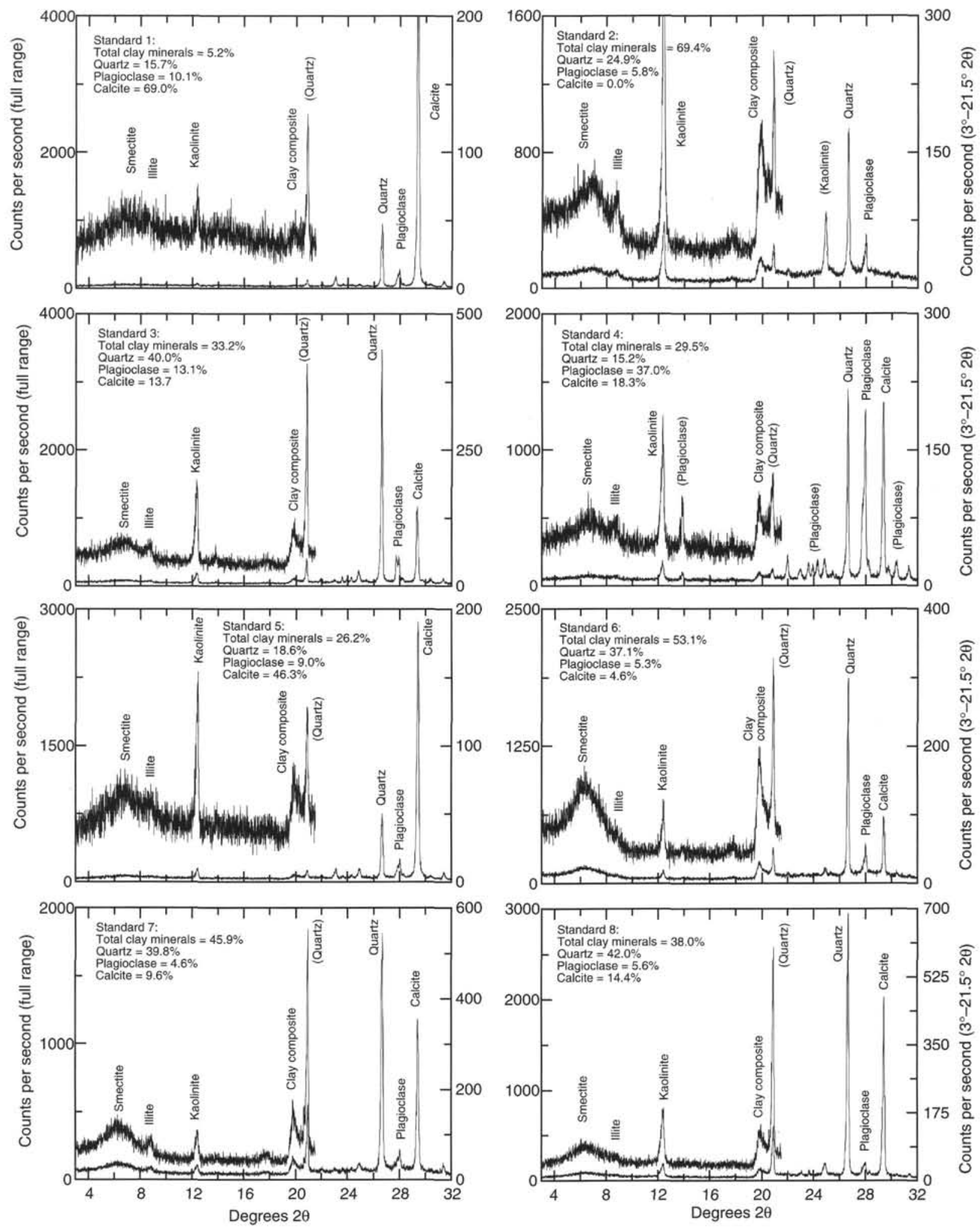

Figure 1. Annotated X-ray diffractograms from nine mixtures of laboratory standards showing characteristic peaks used to estimate mineral abundances. Measured weight percentages are shown for each mineral group in each mixture. For each standard, a portion of the diffractogram with key clay mineral peaks is shown at an expanded scale of peak intensity (upper diffractogram). Peaks labeled in parentheses correspond to reflections that are diagnostic of mineral presence but were not used in the calculations described in this paper. The quartz peak at $3.34 \AA$ was selected as a primary indicator so that direct comparisons could be made with Cook et al. (1975) and because the cluster of quartz, calcite, and plagioclase peaks was convenient for fitting. 


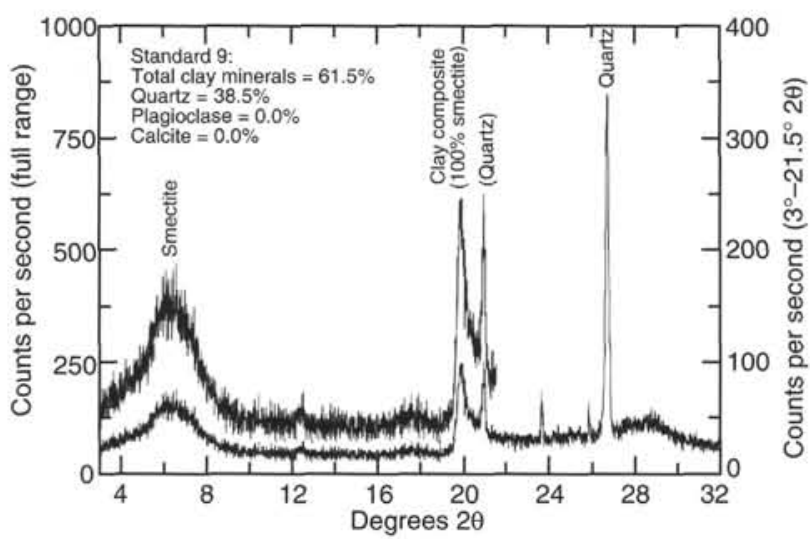

Figure 1 (continued).

specimens, which were obtained from physical properties residues. Smectite interlayer water is partially expelled during oven-drying; even though this is accepted part of the shipboard procedure for measurements of water content and dry density, it creates an XRD artifact by distorting the d-spacing of the smectite (001) reflection. Thus, whereas the values of [smectite + illite] may be reasonably accurate, the smectite-to-illite ratios definitely are not. Proper postcruise investigations of clay-sized separates will yield much better estimates of the clay-mineral abundances, based on oriented aggregates and appropriate solvation and heating techniques.

Use of a composite clay-mineral peak (e.g., the peak at approximately $19.8^{\circ} 2 \theta$ ) is also problematic because its intensity varies with both the abundance of each individual clay mineral and the specific chemical and crystallinity characteristics of that mineral. Ideally, the composite peak changes as a function of total clay-mineral abundances, but this change will also be consistently proportional to variations in the sum of the individual clay-mineral peaks. For this ideal to be tested successfully, similar responses must be recorded for clays in the calibration mixtures and clays in the natural sediment mixtures. We discovered that the match between composite peak response and the sum of individual peak responses was erratic when natural Leg 156 claystones were compared to the artificial laboratory mixtures (Fig. 3). In other words, there are significant differences in clay chemistry, crystallinity, or both, suggesting that use of the composite clay peak will give erroneous results in most cases. Accordingly, unless clay mineral standards are extracted from the same Leg 156 claystones that are to be analyzed for detailed clay mineralogy, we have no way of accurately calibrating the composite peak at $19.8^{\circ} 2 \theta$. This problem provides an additional explanation for the imperfect match between data derived from Leg 110 and Leg 156 shipboard methods, as documented below.

The Cook et al. (1975) method uses peak intensities relative to that of quartz, such that:

$$
A_{i}=\frac{C_{i} \times I_{i}}{\sum_{n=1}^{m} C_{n} \times I_{n}},
$$

where $A_{i}$ is the abundance of mineral $i, I_{i}$ is the peak intensity, $C_{i}$ is a constant used to transform intensity into abundance, and $m$ is the number of minerals. Cook et al. (1975) provided the following values of $C_{i}$ for the minerals of interest: smectite (3.00), illite (6.00), kaolinite (4.95), quartz (1.00), plagioclase (2.80), and calcite (1.65). In the case of the Leg 156 standard mixtures, this formulation leads to large systematic underestimates in total clay content, systematic overestimates of calcite abundance, and inconsistent errors with respect to quartz and feldspar (Table 3).

Mascle et al. (1988) calibrated proprietary Philips software that was designed for quantitative analysis with measurements of six mixtures of unspecified mineral standards. The corresponding constants for net peak intensities (after background correction) are: clay composite $=$ $0.6012 \times 10^{-2} ;$ quartz $=0.3002 \times 10^{-3} ;$ plagioclase $=0.1365 \times 10^{-2} ;$ calcite $=0.3087 \times 10^{-3}$ (J. Tribble, pers. comm., 1994). Application of these values toward the data from Leg 156 standard mixtures yields a better fit for calcite, at least with respect to the $C_{i}$ values of Cook et al. (1975), but the fits for quartz, plagioclase, and total clay remain relatively poor (Table 3 ). We attribute part of the problem to the use of the composite clay-mineral peak by Mascle et al. (1988).

We achieved better results using simple linear regressions of either peak area or peak intensity vs. standard mineral abundance, but errors for some minerals are erratic and still exceed 10\% (Table 3; Fig. 4). These errors are greater than experimental uncertainty and are still considered unacceptable. The best match between actual and calculated mineral abundances was obtained through matrix SVD (Table 3). We evaluated both peak area and peak intensity as indicator signals for each mineral; both types of values were multiplied by the appropriate set of target mineral factors, as in equation 5, to calculate the raw "abundance" of each mineral. Raw abundances less than zero were set equal to zero (but still tabulated as present in trace amounts), and remaining abundances were normalized (proportionately adjusted) so that they total $100 \%$. Errors turned out to be $4 \%$ or less for all minerals in the nine standard mixtures, and in most cases the errors are less than $2 \%$ (Table 3 ). These errors are well within the range of experimental reproducibility. In no case did we encounter a negative raw abundance less than $-2 \%$, despite the wide range in sample compositions. Similar results were obtained using peak areas and peak intensities, although we believe that peak areas are more robust overall, particularly with respect to analysis of broad peaks generated by poorly crystalline clay minerals such as smectite. The peak-area normalization factors for the Leg 156 standards are listed in Table 4.

Figure 5 illustrates a direct comparison of calculated mineral abundances for Leg 156 claystones, as determined by the Cook et al. (1975), Mascle et al. (1988), and matrix SVD methods. These data are based on analyses of trimmings from interstitial water samples from Site 948 , and the compositional range is representative of the overall stratigraphy recovered during Leg 156. Differences among the calculated mineral abundances are as large as $40 \%$ for calcite, plagioclase, and total clay. In addition to these tests, bulk mineral abundances were calculated for all of the shipboard physical properties residues and interstitial water trimmings using the matrix SVD method; those results are presented in the "Lithostratigraphy and Sedimentology" sections in the "Site 948" and "Site 949" chapters (this volume).

\section{Discussion}

What is the actual physical meaning of the individual normalization factors that we calculated using matrix SVD? Strictly speaking, these numbers are no more than a mathematical convenience. It is worth noting, however, that the factor with the largest value is always that of the target mineral. In other words, the factor for quartz exerts the most influence on the calculated weight percentage of quartz, and the factor for calcite is the most important for calculating the weight percentage of calcite. For some minerals, the difference in factor magnitude is several orders magnitude (e.g., illite, kaolinite), whereas for others the differences are smaller (Table 4).

Some factors for nontarget indicators (e.g., quartz as an indicator for illite) are negative. Peak overlap should result in the calculation of positive nontarget factors. Unlike earlier workers (e.g., Heath and Pisias, 1979), however, we believe that it may be experimentally reasonable to have negative nontarget factors, particularly because we did not normalize signals prior to processing. Clay minerals have a preferred orientation due to the nature of their crystallinity. The presence of varying proportions of nonclay minerals could contribute (in a nonlinear fashion) to a lesser degree of clay mineral orientation in bulk-powder, random mounts. There may be other negative contributions related to the density of different mineral grains and the 
Figure 2. Mixing curves for two montmorillonite standards and quartz, expressed in terms of peak intensity and integrated peak area. Specimens of generic Wards montmorillonite and CMS Na-montmorillonite were spiked with measured weight percentages of quartz to solve for the amount of quartz contamination in each standard. These curves were not used quantitatively for the method described in this paper, but they do illustrate the nonlinear interference one mineral can exert on another.
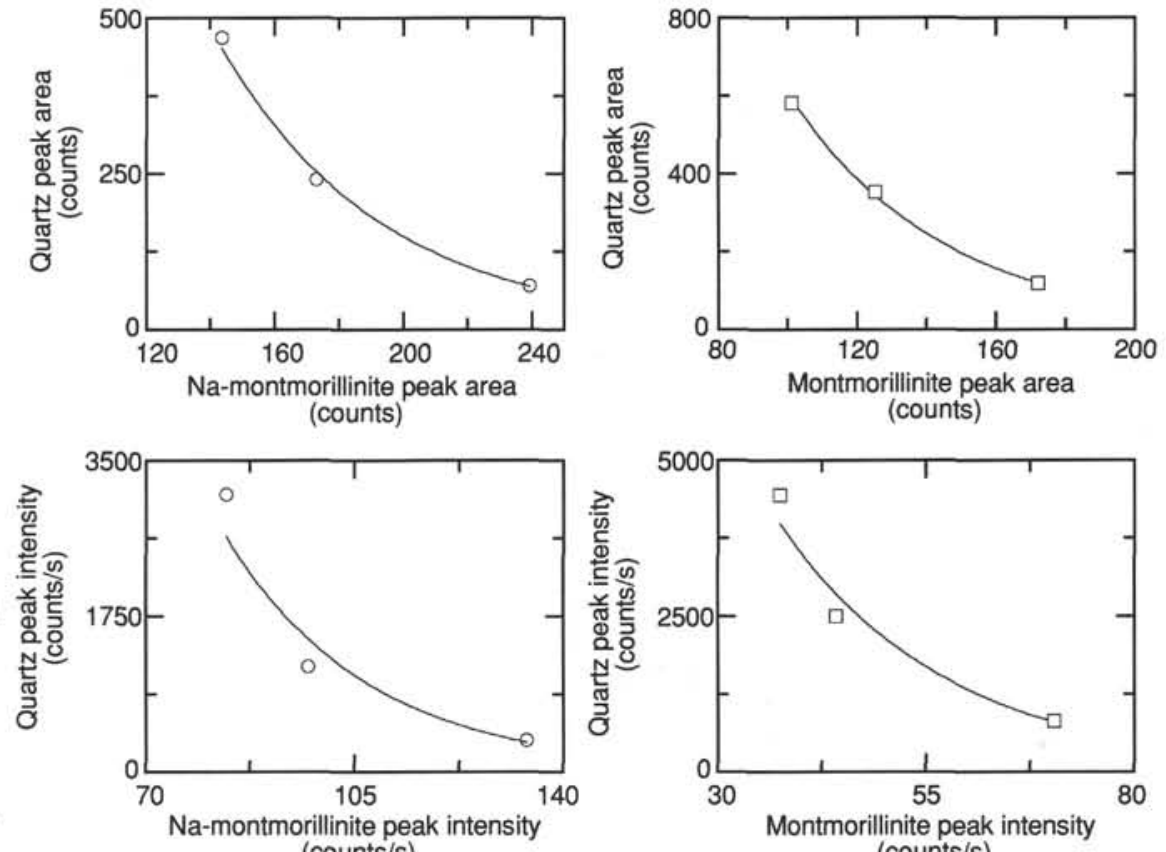

(counts/s)

(counts/s)

Table 2.X-ray diffraction data for mixtures of mineral standards.

\begin{tabular}{|c|c|c|c|c|c|c|c|c|c|c|c|c|c|c|}
\hline \multirow{2}{*}{$\begin{array}{l}\text { Mineral } \\
\text { standard }\end{array}$} & \multicolumn{7}{|c|}{ Peak intensity above background (counts/s) } & \multicolumn{7}{|c|}{ Integrated area after peak fitting (total counts) } \\
\hline & Smectite & Illite & Kaolinite & Clay & Quartz & Plagioclase & Calcite & Smectite & Illite & Kaolinite & Clay & Quartz & Plagioclase & Calcite \\
\hline IA & 6.3 & 3.1 & 15.8 & 7.1 & 635.5 & 158.2 & 3708.2 & 21.7 & 0.4 & 2.9 & 2.3 & 69.3 & 24.3 & 511.5 \\
\hline IB & 10.0 & 4.5 & 17.6 & 6.0 & 803.4 & 259.5 & 4215.8 & 35.7 & 3.6 & 4.0 & 3.2 & 111.8 & 41.5 & 677.4 \\
\hline IC & 9.9 & 3.5 & 17.3 & 6.5 & 691.5 & 167.9 & 4729.7 & 45.0 & 2.2 & 3.4 & 0.8 & 90.8 & 36.9 & 657.3 \\
\hline Ave. \#1 & 8.7 & 3.7 & 16.9 & 6.5 & 710.1 & 195.2 & 4217.9 & 34.1 & 2.1 & 3.4 & 2.1 & 90.6 & 34.2 & 615.4 \\
\hline $2 \mathrm{~A}$ & 38.7 & 26.0 & 222.9 & 75.0 & 589.9 & 192.6 & 0.0 & 124.1 & 14.4 & 66.0 & 54.2 & 99.2 & 28.0 & 0.0 \\
\hline $2 \mathrm{~B}$ & 35.7 & 23.7 & 223.6 & 72.8 & 700.7 & 227.2 & 0.0 & 106.4 & 13.9 & 61.3 & 55.1 & 100.3 & 26.5 & 0.0 \\
\hline $2 \mathrm{C}$ & 42.9 & 29.1 & 270.6 & 77.0 & 899.9 & 214.7 & 0.0 & 149.6 & 13.7 & 72.4 & 33.5 & 140.9 & 28.7 & 0.0 \\
\hline Ave. \#2 & 39.1 & 26.3 & 239.0 & 74.9 & 730.2 & 211.5 & 0.0 & 126.7 & 14.0 & 66.6 & 47.6 & 113.5 & 27.7 & 0.0 \\
\hline $3 \mathrm{~A}$ & 19.6 & 12.8 & 78.6 & 34.4 & 1513.3 & 215.2 & 574.6 & 61.7 & 5.7 & 21.4 & 20.8 & 274.9 & 63.6 & 96.0 \\
\hline $3 \mathrm{~B}$ & 13.1 & 10.8 & 91.7 & 35.1 & 3731.1 & 469.7 & 985.8 & 63.7 & 5.8 & 22.3 & 19.9 & 428.8 & 67.9 & 151.4 \\
\hline $3 \mathrm{C}$ & 21.3 & 13.7 & 100.8 & 35.1 & 2951.7 & 571.2 & 996.7 & 66.7 & 7.3 & 26.5 & 29.5 & 348.8 & 80.0 & 136.8 \\
\hline Ave. \#3 & 18.0 & 12.4 & 90.4 & 34.8 & 2732.0 & 418.7 & 852.4 & 64.0 & 6.3 & 23.4 & 23.4 & 350.8 & 70.5 & 128.1 \\
\hline $4 \mathrm{~A}$ & 18.1 & 11.5 & 82.8 & 30.8 & 1144.3 & 1204.1 & 1120.9 & 56.5 & 7.7 & 24.4 & 15.1 & 144.2 & 188.6 & 161.5 \\
\hline $4 B$ & 17.7 & 12.8 & 82.8 & 26.8 & 681.9 & 871.6 & 1872.6 & 65.2 & 7.4 & 22.8 & 19.9 & 96.6 & 170.5 & 251.6 \\
\hline Ave, \#4 & 17.9 & 12.1 & 82.8 & 28.8 & 913.1 & 1037.9 & 1496.8 & 60.8 & 7.5 & 23.6 & 17.5 & 120.4 & 179.6 & 206.5 \\
\hline $5 \mathrm{~A}$ & 18.4 & 11.0 & 71.4 & 23.0 & 585.9 & 181.9 & 2346.8 & 67.4 & 5.9 & 17.1 & 18.9 & 90.6 & 41.0 & 387.1 \\
\hline $5 B$ & 15.8 & 8.1 & 63.9 & 20.9 & 564.6 & 262.9 & 2596.8 & 63.2 & 4.2 & 16.3 & 15.8 & 82.1 & 42.7 & 418.2 \\
\hline Ave. \#5 & 17.1 & 9.5 & 67.7 & 21.9 & 575.2 & 222.4 & 2471.8 & 65.3 & 5.0 & 16.7 & 17.3 & 86.4 & 41.8 & 402.7 \\
\hline $6 \mathrm{~A}$ & 52.4 & 5.7 & 31.3 & 81.1 & 832.2 & 39.8 & 170.8 & 185.2 & 2.0 & 9.2 & 53.6 & 139.2 & 52.1 & 32.6 \\
\hline $6 B$ & 38.0 & 3.6 & 27.7 & 76.3 & 1286.9 & 47.2 & 768.3 & 136.1 & 0.6 & 7.4 & 51.3 & 172.7 & 38.6 & 73.3 \\
\hline $6 \mathrm{C}$ & 59.7 & 9.6 & 39.7 & 82.8 & 1449.5 & 161.7 & 463.7 & 202.6 & 1.6 & 10.6 & 53.6 & 182.3 & 44.1 & 60.7 \\
\hline Ave. $\# 6$ & 50.0 & 6.3 & 32.9 & 80.1 & 1189.5 & 82.9 & 467.6 & 174.6 & 1.4 & 9.1 & 52.8 & 164.7 & 44.9 & 55.5 \\
\hline $7 \mathrm{~A}$ & 39.9 & 15.5 & 38.9 & 64.4 & 1850.7 & 208.2 & 752.6 & 144.6 & 9.4 & 9.1 & 43.2 & 282.9 & 37.8 & 107.0 \\
\hline $7 \mathrm{~B}$ & 42.8 & 20.1 & 40.5 & 59.7 & 1386.9 & 72.1 & 892.5 & 143.8 & 8.6 & 12.0 & 50.8 & 218.1 & 35.3 & 144.2 \\
\hline $7 C$ & 38.3 & 15.0 & 34.5 & 61.8 & 2019.0 & 90.8 & 735.5 & 122.4 & 7.4 & 9.3 & 39.4 & 235.8 & 31.3 & 127.8 \\
\hline Ave. \#7 & 40.3 & 16.9 & 38.0 & 62.0 & 1752.2 & 123.7 & 793.5 & 136.9 & 8.5 & 10.1 & 44.5 & 245.6 & 34.8 & 126.3 \\
\hline $8 \mathrm{~A}$ & 33.1 & 7.6 & 90.8 & 49.6 & 2341.7 & 87.6 & I378.4 & 115.5 & 5.1 & 31.5 & 36.0 & 349.4 & 33.3 & 222.5 \\
\hline $8 B$ & 32.8 & 8.8 & 111.0 & 43.4 & 1933.6 & 99.3 & 1221.5 & 116.6 & 5.7 & 32.5 & 33.7 & 315.3 & 29.1 & 191.4 \\
\hline Ave. \#8 & 33.0 & 8.2 & 100.9 & 46.5 & 2137.7 & 93.5 & 1300.0 & 116.1 & 5.4 & 32.0 & 34.9 & 332.4 & 31.2 & 207.0 \\
\hline 9 & 72.6 & 0.0 & 0.0 & 117.2 & 639.0 & 0.0 & 0.0 & 231.3 & 0.0 & 0.0 & 72.2 & 98.8 & 0.0 & 0.0 \\
\hline
\end{tabular}

Notes: The quantitative composition of mineral standards are described in the text and listed in Table 1. Most standard mixtures were run several times; results of individual runs and averages (when there was more than one run) are listed above. XRD values for "Clay" are based on the composite peak, while those for individual clays are based on separate peaks. See discussion in text.

degree to which various phases settle prior to and during mount preparation. Negative factors certainly should be smaller in magnitude than those for the target minerals. So long as a wide enough range in standard compositions is selected, the appearance of negative apparent raw abundances will be kept to a minimum. If large negative factors appear, then it is likely that one or more of the primary assumptions was violated. Given this circumstance, additional standards should be mixed to be more representative of the natural mineralogy, or a nonlinear construction should be considered. If the goal is to develop an accurate experimental method for XRD analysis, then preventing the determination of negative factors should be avoided, as such prevention can mask the violation of a primary assumption.

Negative normalization factors (and perhaps all factors for minerals other than the target) can be considered as corrections, necessary because of interference on the diffractograms. The use of only "primary" normalization factors (quartz for quartz, etc.) determined with SVD results in errors that are greater than the errors based on independent linear regressions for each mineral. This is perhaps not surpris- 

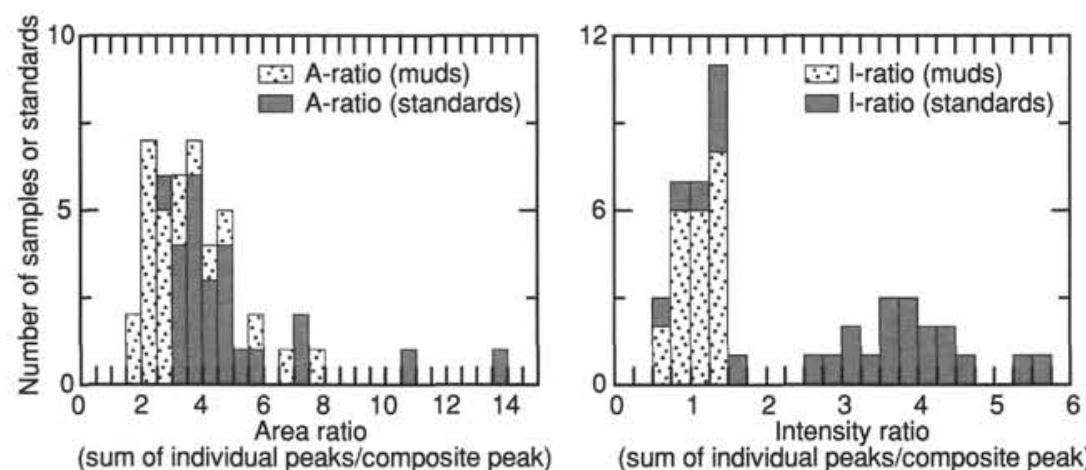

Figure 3. Histograms showing the relations between intensity and peak area for the composite clay mineral peak (at $19.8^{\circ} 2 \theta$ ) and the sum of individual intensity and peak-area values for three individual clay peaks [smectite (001), illite (001), and kaolinite (001)]. There is one standard value with an area ratio of 62 , off the right of the plot. Ideally, for mixtures involving uniform clay chemistry and crystallinity, these values should be consistently proportional. The poor match between natural Barbados clays and laboratory clay-mineral standards indicates that the composite peak

(sum of individual peaks/composite peak) cannot be calibrated accurately using shipboard standards.
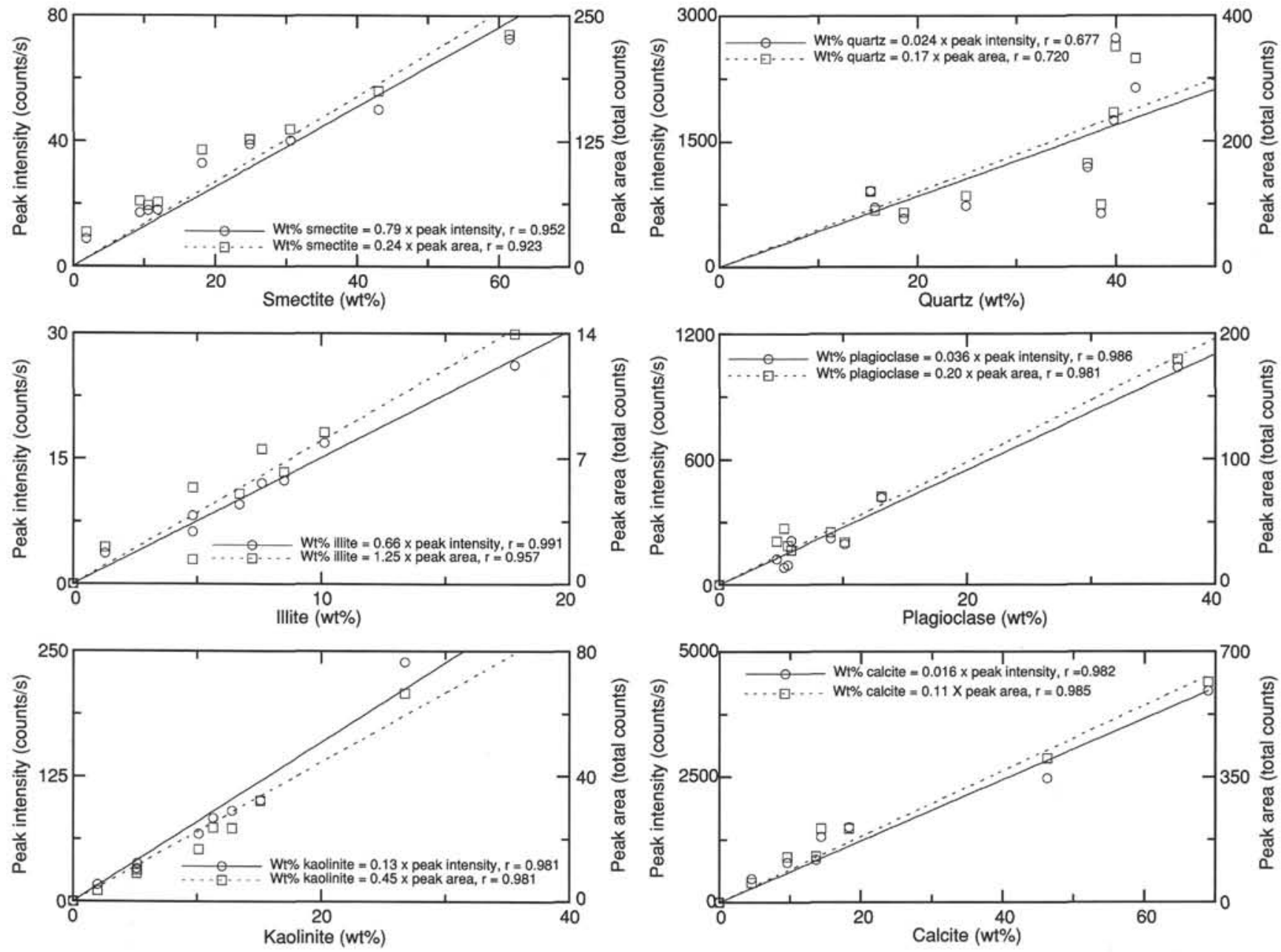

Figure 4. Peak areas and peak intensities vs. mineral abundances for the six mineral standards used in this study. See text for identification of specific mineral sources. Linear least-squares best-fitting lines are shown along with regression coefficients. The correlations are significant to the $99 \%$ confidence level, except for quartz, where the correlation is significant to the $97 \%$ level. The errors associated with using these linear relationships are greater than experimental uncertainty, as shown in Table 3.

ing, as a simple linear regression more effectively optimizes for the best-fitting solution when only a single dependent variable is allowed.

We also experimented mathematically with normalizing peak areas and peak intensities prior to solving for weighting factors by SVD. While this did allow calculation of raw abundances that come closer to totaling $100 \%$, the factors generated through these analyses seemed less physically reasonable. In several cases, the largest factors were those of minerals other than the target, and in one case, the factor with the greatest scaler value was negative. We believe, therefore, that it is better to solve for normalization factors without overly constraining their values through prior normalization of signals.

\section{Recommendations for Improvement}

The normalization factors calculated during this shipboard investigation are valid only for the minerals and the ranges of abundances used in our standard mixtures. The presence of either additional phases or similar phases having different chemical compositions or crystallinities could create significant mismatches. However, the consistency of results with natural samples, and the lack of predicted negative raw abundances with magnitudes greater than $2 \%$, indicate that the method is effective for semiquantitative comparisons. It probably is not possible to derive a fully quantitative method involving 
Figure 5. Comparison of relative mineral percentages calculated from a subset of Leg 156 XRD data using the SVD method described in this paper, and with the methods described in Cook et al. (1975) and data from Leg 110 (Mascle et al., 1988). Leg 156 specimens were obtained from trimmings of interstitial water samples at Site 948.

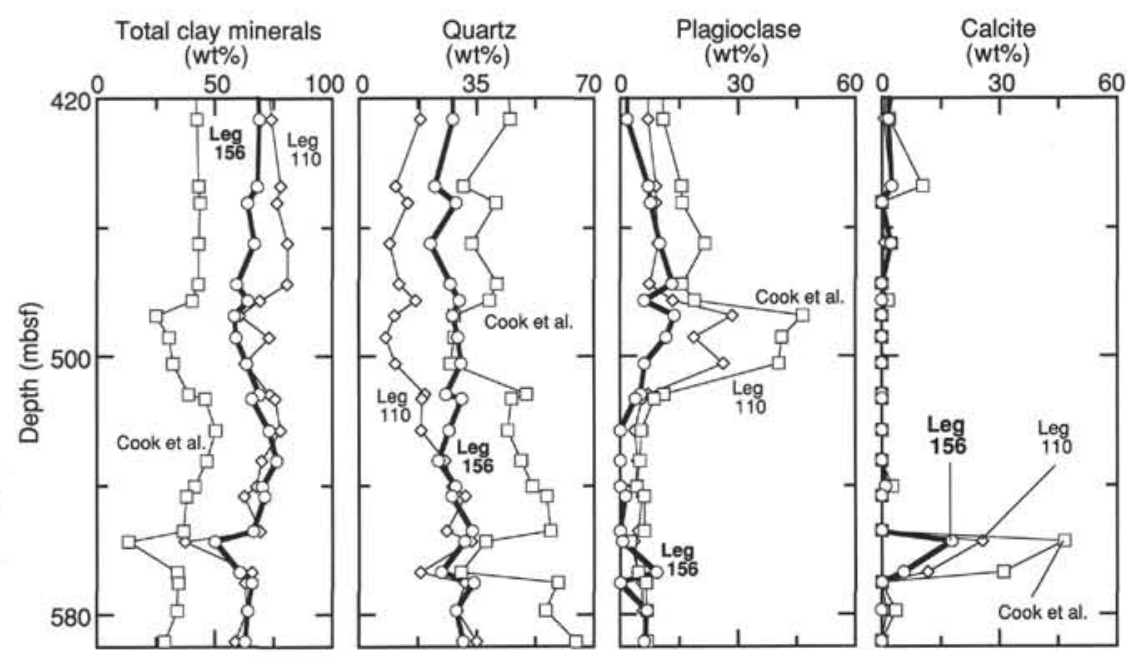

random mounts of bulk powders, as variations in crystallinity and preferred orientation of individual minerals will limit reliability, resolution, and the degree of dependance on preparation techniques.

While it is clear that the SVD method works well with standards of known composition, this study was made easier because previous investigations of the Barbados accretionary prism had identified the dominant mineral phases. In cases where the mineralogy is completely unknown, it might be best to run several pilot samples and then generate a set of preliminary standard mixtures for a first attempt at calibration. As more diffractograms are generated and samples are analyzed using the first set of normalization factors, additional standard mixtures can be created to improve the match. Two or three iterations might be necessary to optimize the selection of minerals and ranges of abundance in the standard mixtures, ideally with many more standard mixtures than minerals.

If, in a particular geologic setting, the use of constant normalization factors proves incapable of providing sufficient accuracy, or if excessively negative raw abundances are generated, then one might use a similar iteration scheme to develop more comprehensive relationships. Such a relationship could include factors that vary with abundance (i.e., $F_{Q Q}=F_{Q Q 2} \times A_{Q}$, etc.). One could find an initial solution using constant factors, then iterate for offset and slope factors, or offset and exponential factors, or factors with whatever mathematical form is required to provide a sufficiently accurate fit for the standard mixtures. The primary limitation of this approach is that investigators must create a large enough number of standard mixtures to assure that there are more equations than unknowns in the matrix being solved. One must also be careful that the varying mineral proportions in these mixtures are sufficiently different so as to avoid linear redundancy (i.e., where the ratios of several mineral abundances are the same in several mixtures). The SVD technique also lends itself to solution of undetermined sets of equations (Press et al., 1986), but this might be particularly risky in the case of bulk XRD analysis, as there are already errors of unknown magnitude introduced by the presence of unanticipated mineral phases and amorphous solids.

\section{ACKNOWLEDGMENTS}

We thank the crew and staff aboard the JOIDES Resolution for their assistance during sample acquisition. Mary Ann Cusimano was particularly helpful during preparation and analysis of the standard mineral mixtures. The manuscript benefited from reviews by Bill Busch and Jane Tribble.

\section{REFERENCES}

Brindley, G.W., 1980. Quantitative X-ray mineral analysis of clays. In Brindley, G.W., and Brown, G. (Eds.), Crystal Structures of Clay Minerals and their X-ray Identification. London Mineral. Soc. Monogr., 5:411-438.
Capet, X., Chamley, H., Beck, C., and Holtzapffel, T., 1990. Clay mineralogy of Sites 671 and 672, Barbados Ridge accretionary complex and Atlantic abyssal plain: paleoenvironmental and diagenetic implications. In Moore, J.C., Mascle, A., et al., Proc. ODP, Sci. Results, 110: College Station (Ocean Drilling Program), 85-96.

Cook, H.E., Johnson, P.D., Matti, J.C., and Zemmels, I., 1975. Methods of sample preparation and X-ray diffraction data analysis, X-ray Mineralogy Laboratory, Deep Sea Drilling Project, University of California, Riverside. In Hayes, D.E., Frakes, L.A., et al., Init. Repts. DSDP, 28: Washington (U.S. Govt. Printing Office), 999-1007.

Heath, G.R., and Pisias, N.G., 1979. A method for the quantitative estimation of clay minerals in North Pacific deep-sea sediments. Clays Clay Miner., 27:175-184.

Johnson, L.J., Chu, C.H., and Hussey, G.A., 1985. Quantitative clay mineral analysis using simultaneous linear equations. Clays Clay Min., 33:107117.

Mascle, A., Moore, J.C., Taylor, E., and Shipboard Scientific Party, 1988. ODP Leg 110 at the northern Barbados Ridge: introduction and explanatory notes. In Mascle, A., Moore, J.C., et al., Proc. ODP, Init. Repts., 110: College Station (Ocean Drilling Program), 5-25.

Moore, C.A., 1968. Quantitative analysis of naturally occurring multicomponent mineral systems by X-ray diffraction. Clays Clay Min., 16:325-336.

Moore, D.M., and Reynolds, R.C., Jr., 1989. Quantitative analysis. In Moore, D.M., and Reynolds, R.C., Jr. (Eds.), X-ray Diffraction and the Identification and Analysis of Clay Minerals: New York (Oxford University Press), 272-309.

Pierce, J.W., and Siegel, F.R., 1969. Quantification in clay mineral studies of sediments and sedimentary rocks. J. Sediment. Petrol., 39:187-193.

Press, W.H., Flannery, B.P., Teukolsky, S.A., and Vetterling, W.T., 1986. Numerical Recipes: The Art of Scientific Computing: New York (Cambridge Univ. Press).

Pudsey, C.J., 1984. X-ray mineralogy of Miocene and older sediments from Deep Sea Drilling Project Leg 78A. In Biju-Duval, B., Moore, J.C., et al., Init. Repts. DSDP, 78A: Washington (U.S. Govt. Printing Office), 325342.

Tribble, J.S., 1990. Clay diagenesis in the Barbados accretionary complex: Potential impact on hydrology and subduction dynamics. In Moore, J.C., Mascle, A., et al., Proc. ODP, Sci. Results, 110: College Station (Ocean Drilling Program), 97-110.

Underwood, M.B., Orr, R., Pickering, K., and Taira, A., 1993. Provenance and dispersal patterns of sediments in the turbidite wedge of Nankai Trough. In Hill, I.A., Taira, A., Firth, J.V., et al., Proc. ODP, Sci. Results, 131: College Station (Ocean Drilling Program), 15-34.

\footnotetext{
- Abbreviations for names of organizations and publication titles in ODP reference lists follow the style given in Chemical Abstracts Service Source Index (published by American Chemical Society).
}

\section{Ms 156IR-103}


Table 3. Calculated mineral abundances and errors of standard mixtures using various methods.

\begin{tabular}{|c|c|c|c|c|c|c|c|c|}
\hline $\begin{array}{l}\text { Standard } \\
\text { number }\end{array}$ & $\begin{array}{l}\text { Clay } \\
\text { (wt\%) }\end{array}$ & $\begin{array}{l}\text { Quartz } \\
\text { (wt\%) }\end{array}$ & $\begin{array}{l}\text { Plagioclase } \\
\text { (wt\%) }\end{array}$ & $\begin{array}{l}\text { Calcite } \\
\text { (wt\%) }\end{array}$ & $\begin{array}{l}\Delta \text { Clay } \\
\text { (wt\%) }\end{array}$ & $\begin{array}{l}\Delta \text { Quartz } \\
\text { (wt\%) }\end{array}$ & $\begin{array}{c}\Delta \text { Plagioclase } \\
\text { (wt } \%)\end{array}$ & $\begin{array}{l}\Delta \text { Calcite } \\
\text { (wt\%) }\end{array}$ \\
\hline \multicolumn{9}{|c|}{ Cook et al. (1975) weighting factors } \\
\hline 1 & 1.6 & 8.5 & 6.5 & 83.4 & -3.6 & -7.2 & -3.6 & 14.4 \\
\hline 2 & 52.4 & 26.3 & 21.3 & 0.0 & -16.9 & 1.4 & 15.5 & 0.0 \\
\hline 3 & 9.8 & 46.4 & 19.9 & 23.9 & -23.4 & 6.4 & 6.8 & 10.2 \\
\hline 4 & 7.9 & 13,4 & 42.6 & 36.2 & -21.6 & -1.8 & 5.6 & 17.9 \\
\hline 5 & 7.8 & 10.1 & 10.9 & 71.3 & -18.4 & -8.4 & 1.9 & 25.0 \\
\hline 6 & 13.8 & 46.8 & 9.1 & 30.3 & -39.3 & 9.7 & 3.9 & 25.7 \\
\hline 7 & 10.7 & 45.9 & 9.1 & 34.3 & -35.3 & 6.1 & 4.5 & 24.7 \\
\hline 8 & 12.5 & 41.2 & 5.0 & 41.3 & -25.5 & -0.8 & -0.6 & 26.9 \\
\hline 9 & 25.4 & 74.6 & 0.0 & 0.0 & -36.1 & 36.1 & 0.0 & 0.0 \\
\hline \multicolumn{9}{|c|}{ Mascle et al. (1988) weighting factors } \\
\hline 1 & 2.2 & 11.7 & 14.7 & 71.5 & -3.0 & -4.0 & 4.6 & 2.5 \\
\hline 2 & 47.0 & 22.9 & 30.1 & 0.0 & -22.3 & -2.0 & 24.3 & 0.0 \\
\hline 3 & 11.2 & 44.0 & 30.7 & 14.1 & -22.0 & 4.0 & 17.6 & 0.4 \\
\hline 4 & 7.4 & 11.8 & 60.9 & 19.8 & -22.1 & -3.4 & 23.9 & 1.5 \\
\hline 5 & 9.6 & 12.6 & 22.2 & 55.6 & -16.6 & -5.9 & 13.2 & 9.3 \\
\hline 6 & 4.3 .9 & 32.6 & 10.3 & 13.1 & -9.2 & -4.5 & 5.1 & 8.5 \\
\hline 7 & 28.4 & 40.1 & 12.9 & 18.6 & -17.6 & 0.3 & 8.3 & 9.0 \\
\hline 8 & 19.3 & 44.3 & 8.8 & 27.6 & -18.7 & 2.3 & 3.2 & 13.2 \\
\hline 9 & 78.6 & 21.4 & 0.0 & 0.0 & 17.1 & -17.1 & 0.0 & 0.0 \\
\hline \multicolumn{9}{|c|}{ Simple linear regression of abundance vs. peak intensity } \\
\hline 1 & 11.2 & 16.5 & 6.8 & 65.5 & 6.0 & 0.8 & -3.3 & -3.5 \\
\hline 2 & 76.0 & 16.8 & 7.3 & 0.0 & 6.7 & -8.1 & 1.5 & 0.0 \\
\hline 3 & 26.6 & 51.0 & 11.7 & 10.6 & -6.6 & 11.0 & -1.4 & -3.1 \\
\hline 4 & 28.4 & 18.9 & 32.2 & 20.6 & -1.1 & 3.7 & -4.8 & 2.3 \\
\hline 5 & 31.8 & 15.3 & 8.9 & 44.0 & 5.6 & -3.2 & -0.1 & -2.3 \\
\hline 6 & 55.1 & 32.8 & 3.4 & 8.6 & 2.0 & -4.3 & -1.8 & 4.0 \\
\hline 7 & 44.7 & 39.3 & 4.2 & 11.9 & -1.3 & -0.5 & -0.4 & 2.3 \\
\hline 8 & 37.1 & 42.7 & 2.8 & 17.3 & -0.9 & 0.7 & -2.8 & 2.9 \\
\hline 9 & 78.9 & 21.1 & 0.0 & 0.0 & 17.4 & -17.4 & 0.0 & 0.0 \\
\hline \multicolumn{9}{|c|}{ Simple linear regression of abundance vs. peak area } \\
\hline 1 & 12.0 & 15.1 & 6.7 & 66.2 & 6.8 & -0.6 & -3.4 & -2.8 \\
\hline 2 & 75.8 & 18.8 & 5.4 & 0.0 & 6.5 & -6.1 & -0.4 & 0.0 \\
\hline 3 & 27.8 & 49.1 & 11.6 & 11.6 & -5.4 & 9.1 & -1.5 & -2.1 \\
\hline 4 & 30.5 & 18.0 & 31.6 & 20.0 & 1.0 & 2.8 & -5.4 & 1.7 \\
\hline 5 & 30.4 & 15.2 & 8.6 & 45.7 & 4.2 & -3.3 & -0.4 & -0.6 \\
\hline 6 & 52.6 & 30.8 & 9.9 & 6.7 & -0.5 & -6.3 & 4.7 & 2.1 \\
\hline 7 & 43.4 & 37.7 & 6.3 & 12.6 & -2.6 & -2.1 & 1.7 & 3.0 \\
\hline 8 & 36.4 & 42.0 & 4.6 & 16.9 & -1.6 & 0.0 & -1.0 & 2.5 \\
\hline 9 & 76.8 & 23.2 & 0.0 & 0.0 & 15.3 & -15.3 & 0.0 & 0.0 \\
\hline \multicolumn{9}{|c|}{ Singular value decomposition based on peak area } \\
\hline 1 & 5.9 & 16.3 & 9.9 & 67.9 & 0.7 & 0.6 & -0.2 & -1.1 \\
\hline 2 & 68.8 & 25.2 & 6.0 & 0.0 & -0.5 & 0.3 & 0.2 & 0.0 \\
\hline 3 & 32.8 & 42.3 & 15.3 & 9.7 & -0.4 & 2.3 & 2.2 & -4.0 \\
\hline 4 & 29.8 & 14.9 & 35.6 & 19.8 & 0.3 & -0.3 & -1.4 & 1.5 \\
\hline 5 & 25.8 & 18.4 & 10.4 & 45.4 & -0.4 & -0.1 & 1.4 & -0.9 \\
\hline 6 & 51.9 & 38.3 & 3.9 & 5.9 & -1.2 & 1.2 & -1.3 & 1.3 \\
\hline 7 & 46.1 & 38.6 & 4.3 & 11.0 & 0.1 & -1.2 & -0.3 & 1.4 \\
\hline 8 & 38.6 & 39.5 & 4.1 & 17.8 & 0.6 & -2.5 & -1.5 & 3.4 \\
\hline 9 & 60.8 & 37.9 & 1.2 & 0.0 & -0.7 & -0.6 & 1.2 & 0.0 \\
\hline \multicolumn{9}{|c|}{ Singular value decomposition based on peak intensity } \\
\hline 1 & 5.5 & 15.8 & 9.5 & 69.1 & 0.3 & 0.1 & -0.6 & 0.1 \\
\hline 2 & 69.4 & 24.9 & 5.7 & 0.0 & 0.1 & 0.0 & -0.1 & 0.0 \\
\hline 3 & 32.6 & 43,2 & 14.1 & 10.2 & -0.6 & 3.2 & 1.0 & -3.5 \\
\hline 4 & 30.3 & 15.4 & 35.3 & 19.1 & 0.8 & 0.2 & -1.7 & 0.8 \\
\hline 5 & 24.6 & 18.4 & 10.4 & 46.6 & -1.6 & -0.1 & 1.4 & 0.3 \\
\hline 6 & 51.5 & 36.9 & 7.8 & 3.8 & -1.6 & -0.2 & 2.6 & -0.8 \\
\hline 7 & 45.5 & 38.8 & 4.8 & 10.9 & -0.5 & -1.0 & 0.2 & 1.3 \\
\hline 8 & 38.5 & 39.5 & 4.9 & 17.0 & 0.5 & -2.5 & -0.7 & 2.6 \\
\hline 9 & 61.6 & 38.4 & 0.0 & 0.0 & 0.1 & -0.1 & 0.0 & 0.0 \\
\hline
\end{tabular}

Note: $\Delta$ values are determined as (calculated abundance - actual abundance)

Table 4. Normalization factors for Leg 156 bulk XRD samples, based on peak areas, determined with matrix singular value decomposition using nine standards.

\begin{tabular}{|c|c|c|c|c|c|c|}
\hline \multirow{2}{*}{$\begin{array}{l}\text { Indicator } \\
\text { mineral }\end{array}$} & \multicolumn{6}{|c|}{ Target mineral } \\
\hline & Smectite & Illite & Kaolinite & Quartz & Feldspar & Calcite \\
\hline Smectite & $2.6680 \times 10^{-1}$ & $5.5772 \times 10^{-3}$ & $-2.4129 \times 10^{-3}$ & $1.2937 \times 10^{-1}$ & $-4.3829 \times 10^{-3}$ & $2.5689 \times 10^{-3}$ \\
\hline Quartz. & $-1.1867 \times 10^{-2}$ & $-6.5690 \times 10^{-4}$ & $7.3326 \times 10^{-3}$ & $8.7705 \times 10^{-2}$ & $-7.4016 \times 10^{-3}$ & $-1.4640 \times 10^{-2}$ \\
\hline Feldspar & $9.2418 \times 10^{-3}$ & $2.1527 \times 10^{-3}$ & $8.0372 \times 10^{-3}$ & $-2.1873 \times 10^{-2}$ & $2.0165 \times 10^{-1}$ & $-1.5821 \times 10^{-2}$ \\
\hline Calcite & $-1.1726 \times 10^{-2}$ & $-1.6797 \times 10^{-3}$ & $1.7838 \times 10^{-3}$ & $2.3147 \times 10^{-3}$ & $5.5948 \times 10^{-3}$ & $1.1432 \times 10^{-1}$ \\
\hline
\end{tabular}

